\title{
Dilemas éticos de una estudiante de medicina ante la eutanasia. ¿Estaremos preparados los médicos del futuro?
}

\author{
Judith VILELLA, Oriol YUGUERO
}

En los últimos años, la enseñanza de la bioética se ha convertido en fundamental en todos los grados de medicina. De hecho, la docencia en este ámbito se ha visto como una herramienta importante para mejorar nuestra sensibilidad ética y evitar que nos convirtamos en profesionales 'malvados' [1].

Como se ha descrito en artículos previos, hablar de eutanasia es hablar de la buena muerte [2]. Pero para poder hablar de la buena muerte, primero hay que romper el tabú social que ha supuesto el final de vida en nuestra sociedad, y también entre los médicos, profesionales a los que hasta hace poco se nos entrenaba para diagnosticar y curar, para posteriormente explicarnos que el paciente podía rechazar el tratamiento y en breve deberá explicarse que el paciente puede solicitar que le ayudemos en su muerte [3]. ¡Qué cambio tan significativo en tan poco tiempo! Ante ese vértigo, hemos considerado útil compartir con la comunidad científica las consideraciones éticas que como estudiante de medicina puede suponer la eutanasia.

Las asociaciones de pacientes refieren que el suicidio asistido existe, y existe en la clandestinidad, sin garantizar esa dignidad en la muerte a la que apelan aquellos que tan contrarios son a la eutanasia.

¿Por qué hay personas que eligen morir? Creemos que más allá del 'estar cansado de vivir', que no pretende ser más que una banalización, hemos visto pacientes en los que los cuidados paliativos no son la solución porque quizás no padecen dolor, sino angustia. Una angustia por seguir vivo gracias a un respirador, por esperar que esa apnea sea la última, angustia por ver a tu familia padecer cada mañana cuando comprueban que sigues vivo.

Es por eso que, como en todo dilema ético, queríamos hacer una aproximación a través de los principios de la bioética:

- Autonomía. La autonomía es la capacidad de las personas de deliberar sobre sus fines y actuar bajo las decisiones que puedan tomar. Todas las perso- nas tienen derecho a decir por sí mismas y a decidir en previsión del momento en que, por distintas causas, no puedan hacerlo. Respetar la autonomía y la decisión de un paciente de no proseguir con ese sufrimiento y angustia, que en plenas facultades mentales parece éticamente correcto.

- Beneficencia. Apelando al espíritu de la medicina, producir una muerte no parece un beneficio para el enfermo, pero hemos de tener claro que los principios siempre deben analizarse desde la perspectiva del paciente. Para un paciente crónico irreversible quizás lo beneficioso no sea seguir conectado a un respirador con dosis constantes de morfina y midazolam. Para él, lo beneficioso puede ser una muerte controlada y acompañada. Podríamos ver un atisbo de beneficencia en esa decisión.

- No maleficencia. Vinculado con lo anterior. Hemos de evitar el mal con nuestras acciones, pero ¿qué es el mal?, ¿quién lo decide? Permitir a un persona con una demencia incipiente decidir que, en un momento, dado se acabe su vida, porque si estuviera en plenas facultades sufriría al ver a su familia acompañando a un ser que ya no es lo que era. Por lo tanto, podemos evitar un mal, presente y futuro, a un paciente y a quienes lo rodean.

- Justicia. El sistema público debe financiar la eutanasia con los recursos públicos. Deberíamos asegurar que los cuidados paliativos están bien financiados porque, en ese caso, los recursos destinados a la eutanasia serían mínimos. Y facilitar un fármaco y un acompañamiento no supone una sobrecarga para un sistema que debería dedicar mucho más a cuidar a aquellos que tienen opción de vivir de forma confortable mientras la medicina paliativa lo permita.

Tras este pequeño análisis creemos que parece éticamente razonable permitir que quien sufre un pa-
Hospital Universitari Arnau de Vilanova. Lleida, España.

Correspondencia:

Dr. Oriol Yuguero. Hospital Universitari Arnau de Vilanova. Avda. Rovira Roure, 80. E-25198 Lleida.

E-mail: oriol.yuguero@udl.cat (c) 2020 FEM

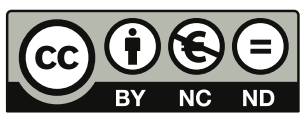

Artículo open access bajo la licencia CC BY-NC-ND (https:// creativecommons.org/licenses/ by-nc-nd/4.0/)

ISSN: 2014-9832

ISSN (ed. digital): 2014-9840 
decimiento insoportable pueda decidir, con garantías y con dignidad, que su padecimiento ha llegado a su fin.

Bibliografía

1. Esquerda M, Pifarré J, Roig H, Busquets E, Yuguero O, Viñas J.
Assessing bioethics education: teaching to be virtuous doctors or just doctors with practical ethical skills. Aten Primaria 2019; 51: 99-104.

2. Sanz-Ortiz J. ¿Es posible gestionar el proceso de morir? Voluntades anticipadas. Med Clin (Barc) 2006; 126: 620-3.

3. Anneser J, Jox RJ, Thurn T, Borasio GD. Physician-assisted suicide, euthanasia and palliative sedation: attitudes and knowledge of medical students. GMS J Med Educ 2016; 33: Doc11. 